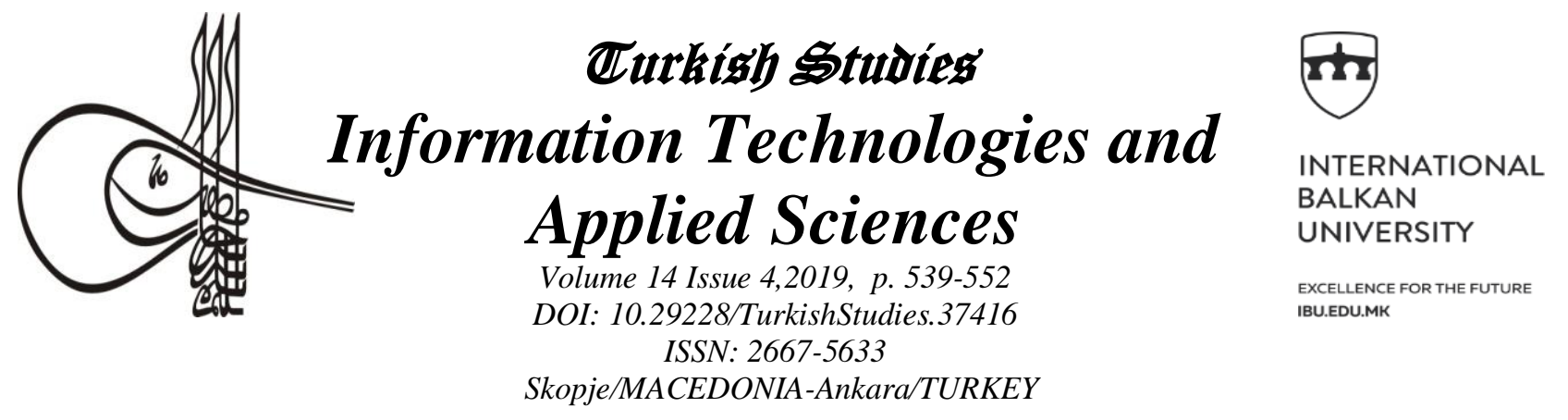

Research Article / Araştırma Makalesi

Article Info/Makale B ilgisi

Received/Geliş: 24.09.2019

VAccepted/Kabul: 30.12 .2019

Go Report Dates/Rapor Tarihleri: Referee 1 (07.12.2019)-Referee 2 (28.12.2019)

This article was checked by intihal.net.

BIG DATA USAGE IN INTERNET ADVERTISING

\author{
İbrahim ATEŞ* - Esra Ayça GÜZELDERELİ YILMAZ ${ }^{* *}$ - Aslihan \\ $T \ddot{U F E K C \dot{I} * *}$
}

\begin{abstract}
As an ever-growing industry, internet advertising incorporates a dynamic structure in which all technological developments are quickly applied. Since the first days of the introduction of the big data concept, many studies have begun on the use of big data in the internet advertising sector. The internet advertising sector, which has been growing and developing since the years when the internet was used individually, cannot be considered independent of big data in the last stage reached.In the coming years, it is expected that the concept of big data will increase the impact of internet advertising and further strengthen its place. In the light of all these developments, both the scientific and commercial technologies and approaches mentioned above are considered to be the subjects to be studied with great care. Nowadays, studies have been carried to very advanced levels and have come to the point of generating income from data. Within the scope of this study, the concept of big data, and how the components of this concept are used in internet advertising have been examined in depth. In addition, some examples are given to the applications of big data usage in internet advertising and detailed explanations are given about the methods and tools used in the application processes. With this study, it is aimed to explain how internet advertising and big data concepts are used together and for what purposes they can be used in the future and to create future assumptions.
\end{abstract}

Lect., Gazi University, E-posta: ibrahimates@gmail.com

Lect., Afyon Kocatepe University, E-posta: eguzeldereli@aku.edu.tr

Assoc. Prof. Dr., Gazi University, E-posta: asli@gazi.edu.dr 


\section{STRUCTURED ABSTRACT}

The increase in internet usage in the world and in our country continues to increase rapidly, causing the big data to grow even more. As the benefit and importance of large data increases, it is expected that more enterprises and institutions will make investments in the big data area.

The internet advertising sector is one of the sectors where big data is used successfully both in the world and in our country. More and more resources are needed in terms of technology and workforce. As a result of the increasingly widespread use of data-oriented marketing, there is a need for well-trained human resources in areas such as data analysis, data-based strategy development, data-driven advertising sales and operations.

From the beginning of the individual use of the Internet to the present, there have been very large technological innovations and transformations. As a communication tool where it is possible to reach large audiencees of users with low costs, the internet is seen as a very attractive advertising medium and the foundations of the internet advertising sector have been laid. Internet advertising, which is the subject of big investments of large capital groups in the world, is also the main activity of Google company which is known all over the world and whose products are used by almost all internet users. From this perspective, it is once again seen how important it is to be a business.

As an ever-growing industry, Internet advertising also incorporates a dynamic structure in which all technological developments are rapidly applied. From the first days of the big data concept into our lives, studies on big data have been started in the internet advertising sector. Nowadays, these studies have moved to a very advanced level and have come to the point of creating income from the data. In this study, it was examined how big data concept and its components are used in internet advertising and the possible developments in the world and in our country are discussed. Examples of big data usage applications were given in Internet advertising, and explanations were also given about the methods and tools used in application processes. In this study, it is aimed to explain how internet advertising and big data concepts are used together and to create future assumptions.

In particular, updating the educational curricula in our universities, strengthening the education programs for the needs of the sector and directing our youth to this field are important in terms of bringing great gains to our country in the short and medium term. In the long term, it will be possible for our country to become a country that exports big data and advertisement technologies to the world, and to provide the national economy by staying abroad within the country due to the foreign products used by the sector.

The internet advertising sector, which has been growing and developing since the 1990s when the internet was used individually, cannot be considered independently from the big data at the last stage. In the following years, it is expected that the concept of big data will increase its influence in the field of internet advertising and will further strengthen its position. In the light of all these developments, the

Turkish Studies - Information Technologies and Applied Sciences Volume 14 Issue 4, 2019 
technology and approaches mentioned in both scientific and commercial fields are considered as the subjects that need to be studied with great care.

Keywords: Internet, Internet advertising, Big data.

\title{
İNTERNET REKLAMCILIĞINDA BÜYÜK VERİ KULLANIMI
}

\begin{abstract}
ÖZ
İnternet reklamc1lı̆g sürekli büyüyen bir endüstri olarak tüm teknolojik gelişmelerin hızlı bir ssekilde uygulama alanı bulduğu dinamik bir yapıyı da bünyesinde barındırmaktadır. Büyük veri kavramının hayatımıza girdiği ilk günlerden itibaren, internet reklamcılığ1 sektöründe büyük veri kullanımı ile ilgili birçok çalışma yapılmaya başlanmıştır. İnternetin bireysel olarak kullanılmaya başlandığ1 yıllardan günümüze dek büyüyerek ve gelişerek ilerleyen internet reklamcilığ bağımsız olarak düşünülememektedir. İlerleyen yıllar içinde büyük veri kavramının internet reklamcılığı alanındaki etkisini arttırması ve yerini daha da sağlamlaştırması beklenmektedir. Tüm bu gelişmeler 1şığında hem bilimsel hem de ticari düzlemde bahsi geçen teknoloji ve yaklaşımlar büyük titizlikle üzerinde çalışılması gereken konular olarak kabul edilmektedir. Günümüzde yapılan çalışmalar çok ileri düzeylere taşınmış ve veriden gelir yaratma noktasına gelmiştir. Bu çalışma kapsamında büyük veri kavramı, ve bu kavramın bilessenlerinin internet reklamcıllğında ne şekilde kullanıldığ derinlemesine irdelenmiş, mevcut durumdan yola çıkarak, dünyada ve ülkemizde gelecekte yaşanması muhtemel gelişmelere değinilmiștir. Ayrıca internet reklamcıllı̆̆ında büyük veri kullanımı uygulamalarına bazı örnekler verilmiş, bu örnekler üzerinden uygulama süreçlerinde kullanılan yöntem ve araçlar hakkında da detaylı açıklamalar sunulmuştur. Bu çalışma ile günümüzde internet reklamcılı̆̆ı ve büyük veri kavramlarının bir arada ne șekilde kullanıldı̆̆ının, gelecekte hangi amaçlarla kullanılabileceğinin anlatılması ve bu anlamda geleceğe dönük varsayımların oluşturulması amaçlanmıştır.
\end{abstract}

Anahtar Kelimeler: İnternet, İnternet reklamcılığı, Büyük veri.

\section{Introduction}

From the beginning of the individual use of the Internet to the present, there have been very large technological innovations and transformations. As a communication tool where it is possible to reach large audiencees of users with low costs, the internet is seen as a very attractive advertising medium and the foundations of the internet advertising sector have been laid. Internet advertising, which is the subject of big investments of large capital groups in the world, is also the main activity of Google company which is known all over the world and whose products are used by almost all internet users. From this perspective, it is once again seen how important it is to be a business.

As an ever-growing industry, Internet advertising also incorporates a dynamic structure in which all technological developments are rapidly applied. From the first days of the big data concept into our lives, studies on big data have been started in the internet advertising sector. 
Nowadays, these studies have moved to a very advanced level and have come to the point of creating income from the data. In this study, it was examined how big data concept and its components are used in internet advertising and the possible developments in the world and in our country are discussed. Examples of big data usage applications were given in Internet advertising, and explanations were also given about the methods and tools used in application processes. In this study, it is aimed to explain how internet advertising and big data concepts are used together and to create future assumptions.

\section{Internet Advertising And Big Data}

Internet advertising can be defined as advertising of goods and services over the internet. The Internet allows for advertising in many different formats. Text ads, display ads, video ads, sponsored content, game ads, mobile ads and email ads are the main ad formats that can be published on the internet.

Internet advertising has different features than traditional advertising tools. The most prominent feature of internet advertising is the interactive feature of the message (Kurcova, 2005). In addition, the wide variety of visual applications on the Internet adds richness to advertisements made over the Internet. One of the most important features of internet advertising that emerges in spite of traditional advertising types is that it provides direct access to the advertised goods or services over the internet. The web is both an area of communication with the customer and a distribution channel as an advertising medium (Korgaonkar \& Wolin, 2002).

Advertising on the internet began on October 27, 1994. On this date, Wired Magazine's online version, Hotwired, is known as the first advertising site on the WWW. Even the directors of the magazine have never dreamed of the great impact that 14 advertisers have had on the site during the online debut of Hotwired. In the future, magazine managers who avoided the use of video, audio and large graphics files due to long download times have discovered a new application called "Banner ad". Large publishers and internet investors have been seeking various ways to use this media more professionally and have started to see web pages as mediums that may include additional messages besides their primary information. In this way, web pages have been created which offer links to various other pages. The Internet, which resembles a brochure with a growing number of pages, has now opened a new market for the advertising sector (Özen and Sar1, 2008). Turkey IAB (Interactive Advertising Bureau), according to 2017 research adex-T Turkey 'digital advertising investments has reached to 2 billion 163 million TL.

Internet; unlike traditional advertising media such as television, newspapers, and open air, it offers a customizable and customizable advertising experience. In this way, enterprises have the opportunity to promote more effectively with smaller advertising budgets. The intensive sales of goods and services via the internet, the development of electronic commerce and digital payment systems drive all sectors and businesses of all sizes to invest in internet advertising. Advertisers are buying advertising spaces from internet sites directly or via advertising agencies with different purchasing models. Different purchase models are available, such as pay-per-view, pay-per-click, and pay-per-membership.

The most important feature that distinguishes the Internet from other advertising channels is that the ads are measurable. Thanks to the continuously developed advertising management and measurement tools, advertising budgets are used more effectively and effectively. Through advertising performance analysis reports, advertisers also know how to run future advertising campaigns. Advanced targeting options allow the right person to show the correct ad in the right place at the right time.

Turkish Studies - Information Technologies and Applied Sciences Volume 14 Issue 4, 2019 


\subsection{Actors in the Internet Advertising Industry}

There are many actors working in different stages of the internet advertising industry. These; advertisers, creative advertising agencies, media planning and purchasing agencies, advertising publishers, ad networks, ad servers and advertising exchanges.

Advertisers are natural or legal persons who use the Internet as an advertising medium for the promotion of the goods and services they produce or sell, and who have certain budgets for these promotional activities.

Creative agencies are the advertising agencies that carry out the creative processes of advertising campaigns such as design and construction, conduct research on the ways in which advertising budgets are used and make usage decisions. At the same time, they carry out the necessary media plans for the publication of their campaigns, and conduct the necessary purchases from the media. Media plans that are approved by advertisers are put into practice together with the start date of the campaign, and all stages up to the end of the campaign are managed by media planning and purchasing agencies. The purchase of Internet ads and the execution of campaigns is carried out by the ve Digital Media Planning units.

Ad publishers are web pages on the internet where advertising is broadcasted. News sites, reference sources, portal and journals, social media sites, mobile games and applications are called ad publishers. Sites operating on the Internet must be able to provide certain conditions for advertising. High and high quality traffic, original and legal content and right ownership are among the main requirements. In accordance with the advertising plan, the publisher publishes all the operational processes of the advertising campaign, which is decided to be published on the publisher site. Publishers are required to provide the number of ad impressions targeted in the media plan. Otherwise, the budget will be recalculated by the advertiser and only paid until the part of the presentation.

It is not possible for each publisher site to establish an advertising sales unit within the body due to the need for both technological infrastructure and trained human resources in advertising sales and operations. At this stage, companies engaged in advertising sales and operation processes of these sites have made agreements with multiple sites. These companies are called the "Ad Network". Ad networks have all necessary technological infrastructure and trained human resources. A large number of ad networks specialized in different categories operate all over the world. The largest known ad network today is Google Ad Sense, a subsidiary of Google, with more than 11 million publishers.

Ad servers are software services that are used to display and measure ads on publisher sites. The operation and reporting processes of advertisements are carried out through these software. Defining the campaign's start date, how long it will be aired, how long it will be shown, how to host advertising visuals or videos, frequency settings of alternating ads, basic operation processes such as user targeting, measurement and reporting of metrics defined in campaign targets, future predictions post-operative processes are carried out through these software. Google AdManager, Sizmek, Adocean by Gemius, Smartadserver, Mopub, Reklamport, AdTech, Advertserve, Appnexus, Adform, OpenX, Revive Adserver, Zedo are the main ad servers commonly used in the world and in our country.

The advertising exchange is the system that combines ad inventory in different ad networks and ad campaigns from different sales channels. Advertising exchanges usually work as a platform provider. When an advertising network is integrated into an exchange, it can evaluate the portion of the advertising inventory in its possession that cannot be directly sold. With the real-time auction method, the publisher that is currently offering the highest bid to the relevant inventory is published

Turkish Studies - Information Technologies and Applied Sciences Volume 14 Issue 4, 2019 
on the publisher site. All transactions are made through software, and publishers can access thousands of ad campaigns by working with only one company. Google Doubleclick AdExchange, Appnexus, Rubicon, Pulsepoint, OpenX and Mopub can be shown as major ad exchanges.

\subsection{Big Data}

In the field of information and communication technologies, information, which has taken its place as a new production factor as well as labor, capital and natural resources as a result of the great developments experienced in recent years, has become the most important resource element in providing organizations a competitive advantage. Innovation is an indispensable requirement for organizations to achieve sustainable competitive advantage. The nature of innovation is also shaped by knowledge. Information is a form of data that has been put into a useful form for managers as a result of a transformation and analysis process in order to reach certain goals or develop a certain understanding (Gökçen, 2011).

Big data is a revolutionary issue in all aspects of our lives, from businesses to consumers and from science to government (Jagadish, 2014). "The view that big data, defined as the petroleum of the knowledge economy, has initiated a major transformation, especially in the humanities, has become a frequently repeated discourse of the last 10 years." (Işıkl1, 2014).

Big data is a new concept that defines heterogeneous data of different volumes that cannot be processed using traditional database techniques and consists of various digital contents (Gahi, Guennoun and Mouftah, 2016):

- Structural data: Structural data refers to all types of data that are easy to model, input, store, query, process, and visualize. In general, certain types and sizes are presented in predefined fields and can be managed in relational databases or tables. In this data type, which has a rigid structure, it is easier to obtain useful information than other data types because the processes do not require high performance capabilities or parallel techniques.

- Semi-structured data: Semi-structured or self-describing data reflects a type of structural data, but does not merely contain a rigid model. In other words, semi-structural data includes models in which structurality is defined, as well as various metadata models, such as labels and markers, which are used to define specific elements and a hierarchical representation of different fields in the data. The most well-known examples of semi-structured data include XML (Extensible Markup Language) and JSON (JavaScript Object Notation) programming languages.

- Non-structured data: Non-structured data are the types of records that are presented and stored outside a defined format. It usually consists of text in free formats such as books, articles, documents, e-mails, and media files such as images, audio and video. The rigorous presentation of this type of data has led to the emergence of new mechanisms in data processing such as NoSQL (Not only SQL).

Today, there are more data sources than yesterday. Many sources feed on big data, such as smartphones, tablet computers, sensors, medical equipment, web traffic records, interactions in social networks, and scientific research offering solutions in areas such as pharmacy, meteorology and simulation (Schneider, 2012). However, the increasing heterogeneity of the web environment leads to the provision of large data content on different web pages (eg text, images and videos), genres (eg encyclopedia, news, blogs) and subjects (eg entertainment, sports, technology) (Achsas and Nfaoui, 2017).

The development of information technologies over time has led to the creation of large and diverse data. Data processing with traditional data management systems can be defined as big data, which is very difficult to process, growing at an ever increasing rate and obtained from a variety of sources. Due to the nature of the big data, it contains a wide range of confidential information. Data

Turkish Studies - Information Technologies and Applied Sciences Volume 14 Issue 4, 2019 
mining from the data carried out to reveal this confidential information is called data mining. Data mining can also be called an information discovery method using open-source or commercial algorithms on large stacks of data that are difficult to process by traditional statistical methods.

\subsubsection{Data Warehouse}

The data warehouse, which was first proposed by William H. Inmon in 1991, is defined as collecting data from various sources in order to support the decisions of management. Briefly, they are the repositories where data collected from many databases are collected. The feature of data warehouses is that it can provide users with different levels of detail. The lowest level of detail relates to the archived record itself, while the higher levels relate to the collection of more information, such as time. Data warehouses require significant investments and take a year or more to implement (Murray and Ned, 1999).

The data warehouse can be thought of as a kind of data base for data mining. While the data collected in the data warehouse is obtained from many different sources, the data in the warehouse cannot be deleted or changed. However, new data can be added to the warehouse at certain intervals. In this way, overloading and data damage to the databases used in daily operations were prevented. Before starting data mining, it is necessary to select the data to be taken to the warehouse and determine the mining purpose. Failure to do so may result in failure.

The data warehouse provides an opportunity to integrate non-integrated applications. The data warehouse provides the basis for the information needed to perform analytical operations within a time dimension. The data warehouse is a collection of read-only, integrated, time-size, read-only data that is prepared to support managers in the decision-making process. Data entries to the data warehouse are mostly made by converting from the operational environment. The data warehouse should always be physically considered separate from the operational environment (Özkan, 2008). Basic features of the data warehouse;

- The data in the operational environment is transferred to the data warehouse as a result of a filtering process. It is not expected that the data in the operational environment will be fully transferred to the data warehouse. Only data that the decision support systems need will be transferred.

- The data in the operational environment is very fresh. The data in the data warehouse is older. In terms of time, there will be a brief overlap between the data in the operational environment and the data in the warehouse.

- Summary data can be found in the data warehouse and summary data is not included in the operational environment.

- In order to provide data integration, which is one of the most important features of the data warehouse, a significant part of the data is transferred to the data warehouse after a certain conversion. Thus, there may be differences in the content of the data in the data warehouse (Özkan, 2008).

When the data warehouse is analyzed in terms of the data it contains, it can be classified as metadata, detail data, old detail data, low level summarized data, and highly summarized data. Metadata does not include data directly from the operational environment. Metadata is a directory created to help decision support systems analysts and indicates what the data warehouse content is. It is a guide that contains information about the location of the transformed environment from the operational environment to the data warehouse. The detail data contains the most recent events and has a larger volume than others because it has not yet been processed. Because such data is stored on the disc, access and management is expensive. With detail data, only the latest detail data is not

Turkish Studies - Information Technologies and Applied Sciences

Volume 14 Issue 4, 2019 
meant. These details may cover a specific period. For example, data on sales may include details of the last five years. The old detail data creates the old detail information that belongs to the older date. This data is stored down to a lower level of detail than the current detail data. Since this type of data is not accessed very often, they can be stored on the disc or they can usually be placed in other storage units. Low-summarized data is the data stored on the disk, summarized at the low level, obtained by filtering out the current detail data. During the design of the data warehouse, it is determined which data will be summarized and the level of the summarization process. High summarized data is the data that is generated by a high level summarization of the instantaneous detail data and can be defined as a component of the data warehouse (Özkan, 2008).

\subsubsection{Areas of Use of Big Data}

Nowadays, big data is widely distributed. Despite the fact that it is still in the early stages of benefiting from big data in commercial life, the use of big data in almost all sectors continues to increase rapidly. Both the development of computer technologies and the continuation of data production with great acceleration led enterprises from all sectors to invest in big data.

Big data provides a way for researchers to find answers to their questions and to predict individual behaviors and community trends (Goes, 2014). In addition, big data are used in many fields from economic and commercial activities to public administration, national security and scientific research. Some of the key objectives of big data applications are improving consumer experience, lowering costs, developing better marketing strategies and increasing the effectiveness of existing processes. In addition, the establishment of security due to the occurrence of data breaches has become one of the purposes of the use of big data. Major application areas of big data include banking, communication, media and entertainment sector, health services, education, production, government services, insurance, retail and trade, transportation, energy sector and selfmeasurement data analysis.

\subsection{Big Data Usage in Internet Advertising}

Today's market structure, consumer needs, lifestyles, technological developments and increasing competition make it compulsory for firms to reach consumers through different means, more frequently and in interesting ways. Along with the ever-increasing competition in growing markets, advertising has become the most basic marketing tool companies use to reach their customers. In order to reach the target audience, as a result of the technological developments and changing consumer preferences, it has added channels such as internet and mobile devices to the traditional media such as radio, television and newspapers. Internet advertising has emerged as a marketing strategy involving the use of the Internet. Internet advertising, which is also referred to as digital or online advertising, has increased its importance with the increase in the number of users as a medium in which many companies have been involved since the 1990s (Arslan, 2017).

Big data is used as an important resource in internet advertising as in all other application areas. The two main purposes of using large data in internet advertising are to ensure that the right person is shown to the right person, at the right time, in the right area, the right advertisement is shown, and advertising fraud is prevented. Many of the information needed to achieve these goals is hidden within the large data collected during the traffic flow on the Internet. Internet advertising companies are working on more efficient advertising systems by revealing the confidential information in this data.

In light of these developments, many software companies in the world are developing software products that will serve the big data usage in advertising. Many products such as data management platforms (DMP), ad verification tools, brand security tools, analytics software and data modeling software are used in the internet advertising industry. The main source of the big data used in internet advertising is visitor data on websites. A visitor to the site from the time he

Turkish Studies - Information Technologies and Applied Sciences Volume 14 Issue 4, 2019 
made a visit to the site during his visit and all the processes on the site through browser cookies can be viewed. Access information such as type of device, geographical location, internet access provider can be matched with the traffic data of the visitor's demographic information if it is a site that is logged on.

Data is usually stored on systems called data management platforms. The biggest feature of these platforms is that they can process huge amounts of data instantly. A data management platform is designed to provide software and hardware requirements that can instantly process data from thousands of visitors. In this way, advertisers and ad publishers can quickly start to do the necessary work to increase their advertising performance by using big data.

\subsubsection{Audience Targeting Methods in Internet Advertising}

Visitors to the Internet are dedicated to specific audiences from the advertiser's perspective. The answer to the question of who the visitors are is very important at this point. All visitors are included in specific target groups. During this process, many confidential information is used in large data. The methods used to target the audiencees can be addressed in five main headings. These; demographic, technology-based, behavioral, remarketing and outsourced data targeting.

In demographic targeting method, visitors are grouped according to demographic characteristics such as age group, gender, income level, education level, geographic location. Visitors included in the groups where the ad is intended to be shown will show the appropriate ad. In technology-based targeting method, visitors are grouped according to the technologies used in accessing the internet such as internet access provider, device and operating system. "Users connected via a $4.5 \mathrm{G}$ connection with an Android operating system", this audience targeting can be shown as one of the sample audiencees in management. In behavioral targeting method,visitors are grouped according to their behavior on the website. Behavioral products such as reviewing certain categories of products, purchasing products at certain intervals, and visiting at certain hours can be shown as examples of the behaviors used in this method. In remarketing, all movements of the visitors from their entrance to the site are monitored. After the visitor leaves the site, the ads that are suitable for the content previously visited on different sites are displayed on the new sites. To take advantage of this method, it is necessary to work with companies that provide remarketing infrastructure. Otherwise, it will be necessary to integrate separately with all the sites where the ads are required to be shown. Finally in external data-based targeting methoduses visitor data obtained from different data providers for a fee or free use. Often, businesses that cannot fully predict the demographic characteristics of their visitors obtain this data from other data providers whose hands are based on demographic visitor data. For example, visitors to a public news site may experience difficulties in estimating the age and gender status of the visitors as the site management visits the site without making members. In this case, site management obtains data from another social media site and reaches the age and gender information of a part of its visitors. Afterwards, all the visitors can be categorized according to specific age and gender groups, and the visitor traffic on the site can be increased by presenting different content that may be of interest to each group.

Also, there are some restrictions for the data to be used in ad targeting. Basically anonymous data is used. Use of personal information is not permitted.

\subsubsection{Target Audience Models in Internet Advertising}

The audiencees that represent the target audience and are created on the basis of only a small section within the general user population can be called the target audience model. The purpose is to expand the model by accessing other users who have similar characteristics in large data, based on the known audience model. For example, in an electronic commerce site, gender and age groups of other visitors with similar behaviors that are similar to those of known visitors can be

Turkish Studies - Information Technologies and Applied Sciences Volume 14 Issue 4, 2019 
estimated. These visitors are included in the relevant gender and age groups. Thus, a relatively small set of visitors can be enlarged using large data and used for purpose.

\subsubsection{Creation of Audience Models and Ad Operations Integration}

Various tools are used to create audience models and use them in advertising operations. This section will explain how to create and use advertising audiences using Google Analytics 360 as a data management platform on a representative news site and Google Ad Manager products as an ad server.

First of all, it is necessary to determine the target audience. In this example, those who follow the economic news on the representative news site are identified as the target audience. As can be understood from the name of the model, the visitor should follow the economic news. It was determined that the visitor should have read at least one economic news in one week.

Google Analytics 360 before you can define an audience, you need to create a audience segment that will meet the audience specifications. To start the segmentation process, first enter the Audience menu. Click the "Add Segment" button at the top of the screen and click "New Segment" button. After entering the segment name in the screen that is opened, the required filter operations are applied and the Save button is clicked and the segment registration process is completed.

In this example, the 'Page' metric should contain the phrase 'economy'. For this reason, the 'Page contains economy' condition is added as a filter from the Advanced> Conditions filter screen.

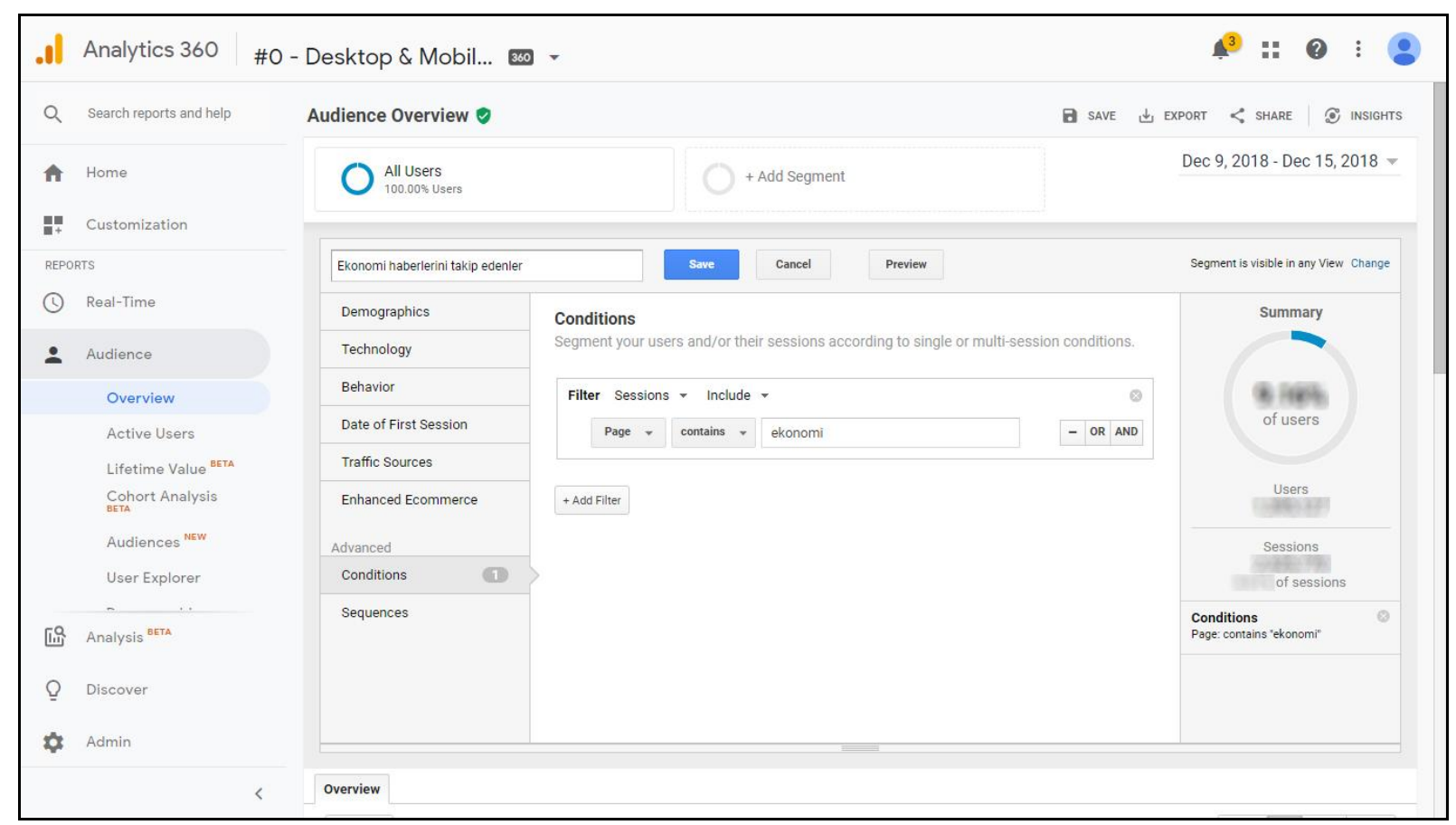

Figure 1. Creation of audience models on Google Analytics 360.

Once the audience segment has been created, it is necessary to create a target audience using this segment and send it to Google Name Manager for use in advertising operation. 
Click on the 'New Audience' button in the Settings> Property> Audiences menu. After clicking on the 'Import Segment' button on the pop-up screen, the previously defined audience segment is selected from the list. Finally, Google Ad Manager (GAM) is selected from the 'Audience Destinations' section and click on the 'Publish' button to complete the transaction.

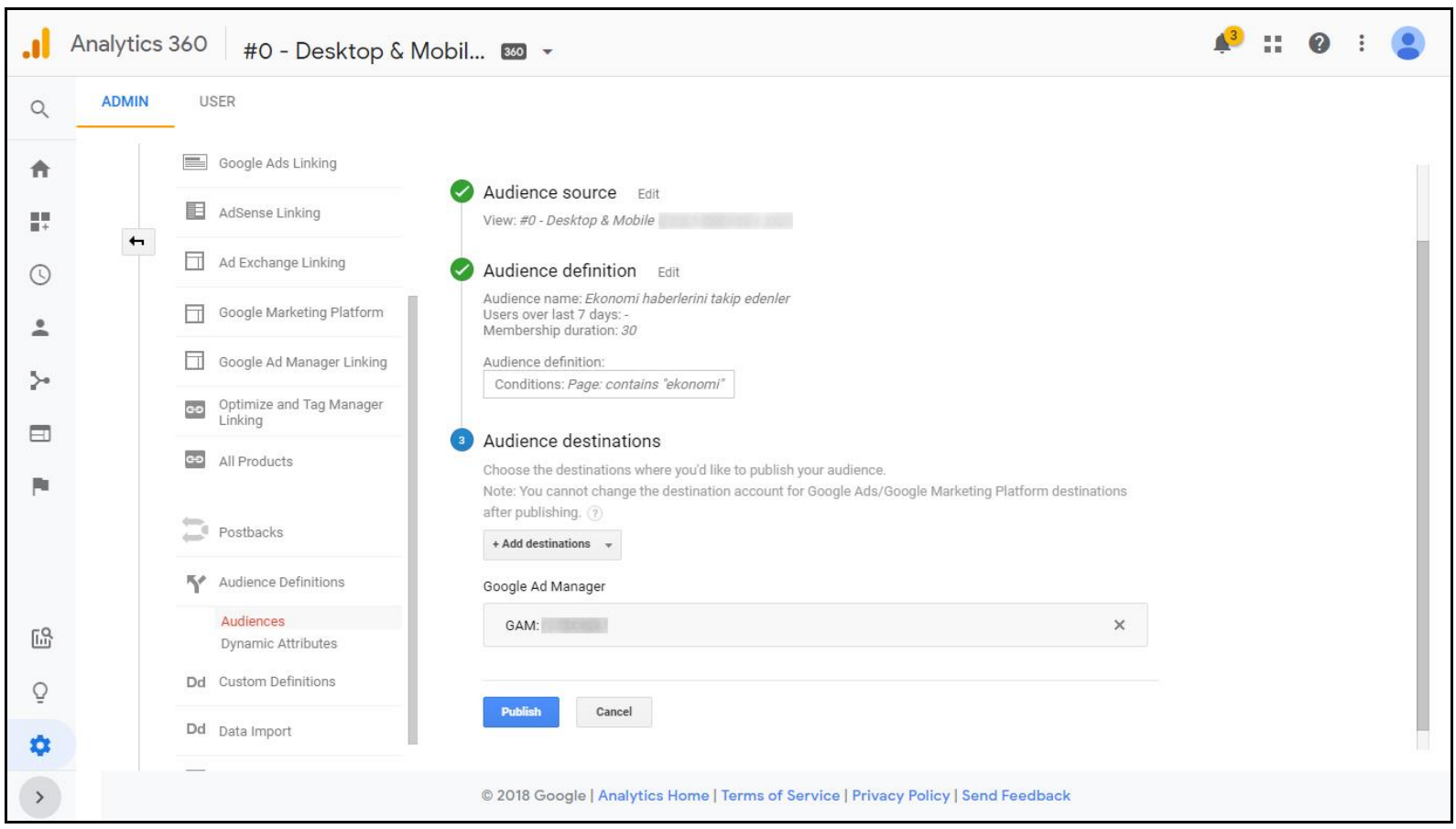

Figure 2. Define the target audience through Google Analytics 360 and submit it to Google Ad Manager.

The target audience sent through Google Analytics 360 is now available in Google Ad Manager for ad operations. With audience targeting, relevant advertising can only be shown to visitors involved in the audience. Ads delivered to the right audience are expected to have a higher performance.

In order to identify the target audience to the ad campaign, the target audience will be typed in the search box that appears after selecting 'Audience Segment' from the 'Key / Value pairs and Audience' filter in the targeting step of the campaign entry screen and the selection is completed. When the campaign setup is finished, the ads will only be shown to visitors to the target audience. 


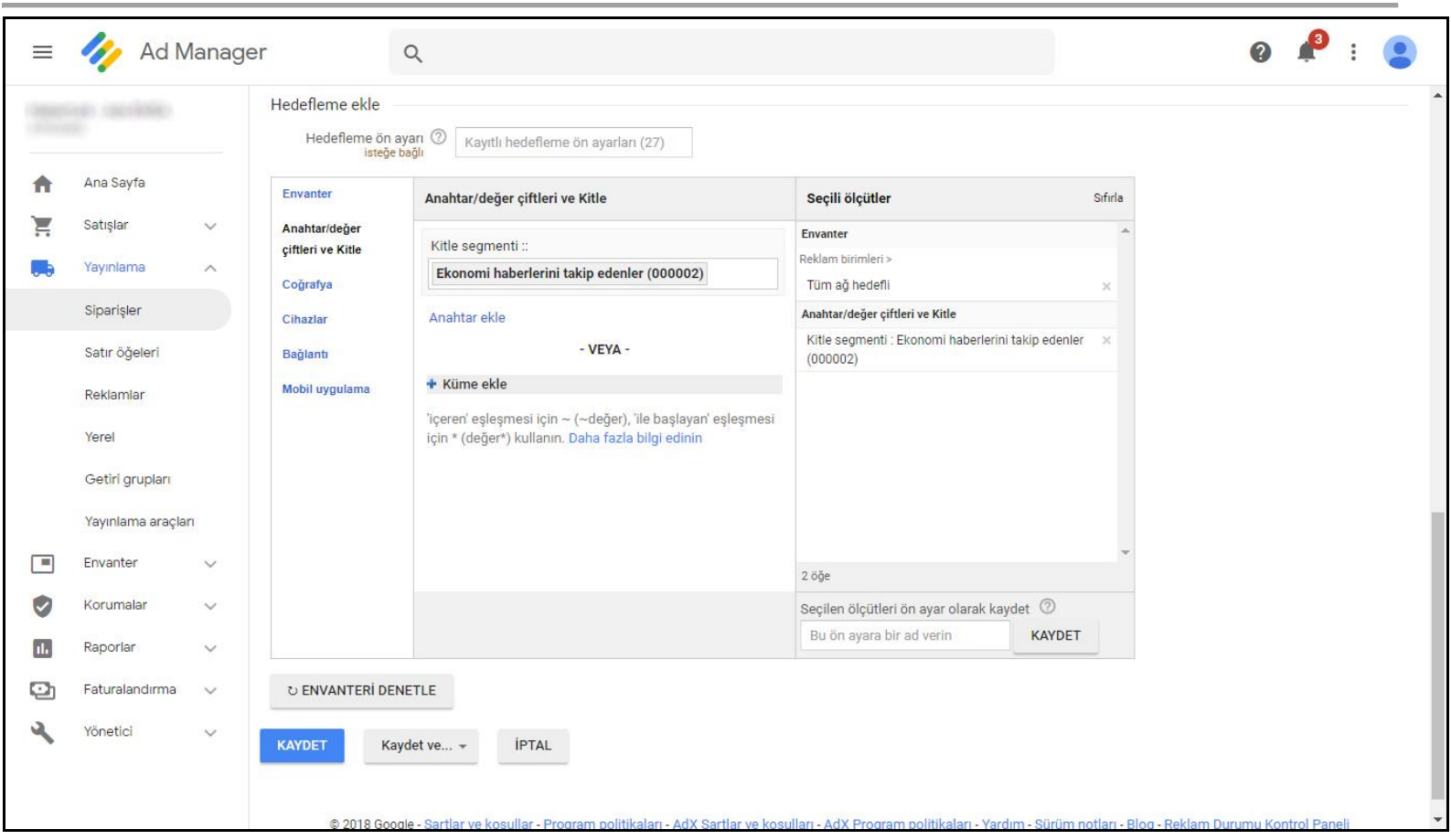

Figure 3. Use of target audience in Google Ad Manager

With the increase of data usage, some legal arrangements have been made in our country and in the world in order to prevent malicious use. These; No. 6698 "Law on the Protection of Personal Data"and "General Data Protection Regulation"(GDPR) in the European Union.

\section{Conclusion}

The increase in internet usage in the world and in our country continues to increase rapidly, causing the big data to grow even more. As the benefit and importance of large data increases, it is expected that more enterprises and institutions will make investments in the big data area.

The internet advertising sector is one of the sectors where big data is used successfully both in the world and in our country. More and more resources are needed in terms of technology and workforce. As a result of the increasingly widespread use of data-oriented marketing, there is a need for well-trained human resources in areas such as data analysis, data-based strategy development, data-driven advertising sales and operations.

In particular, updating the educational curricula in our universities, strengthening the education programs for the needs of the sector and directing our youth to this field are important in terms of bringing great gains to our country in the short and medium term. In the long term, it will be possible for our country to become a country that exports big data and advertisement technologies to the world, and to provide the national economy by staying abroad within the country due to the foreign products used by the sector.

The internet advertising sector, which has been growing and developing since the 1990s when the internet was used individually, cannot be considered independently from the big data at the last stage. In the following years, it is expected that the concept of big data will increase its influence in the field of internet advertising and will further strengthen its position. In the light of all these developments, the technology and approaches mentioned in both scientific and commercial fields are considered as the subjects that need to be studied with great care. 


\section{REFERENCES}

Achsas, S. ve Nfaoui, E. H. (2017, 17-19 Nisan). Improving Relational Aggregated Search from Big Data Sources Using Deep Learning. 2017 Intelligent Systems and Computer Vision (ISCV), Morocco, Fez, 1-6.

Arslan, E. (2017). Natural Advertise in Turkey: An Investigation of advertising in Turkey as a natural method of Internet advertising. Karadeniz Technical University Faculty of Communication Electronic Journal.4(14), 19-42.

Av. Mintaş H. (2018). What is the Law on the Protection of Personal Data? What does it bring?. Journal of Indigo. It was accessed on 20.12.2018 at https://indigodergisi.com/2018/06/kisisel-verilerin-korunmasi-kanunu-nedir-2/ address.

Ay Karakuş B. (2018). Electronik Trade. Firat University Graduate School of Natural and Applied Sciences PhD Thesis, Elazığ.

Bilginç IT Academy. (2017). Industrial Use of Big Data. It was accessed on 19.12.2018 at https://www.bilginc.com/tr/egitim-haber/buyuk-verinin-endustriyel-kullanimi address.

Gahi, Y., Guennoun, M. ve Mouftah, H. T. (2016, 27-30 Haziran). Big Data Analytics: Security and Privacy Challenges. 2016 IEEE Symposium on Computers and Communication (ISCC), Messina, Italy, 952-957.

Goes, P. B. (2014). Big Data and IS Research. MIS Quarterly, 38(3), 3-8.

Gonençoğlu M. (2014). Stages of Data Mining. It was accessed on 17.12.2018 at http://mgocenoglu.blogspot.com/2014/06/veri-madenciligi-asamalar.html address.

Gökçen, H. (2011). Management Information / Information Systems: Analysis and Design. (2nd Edition). Ankara: Afsar Printing.

How Does Ad Serving Work? (2013). It was accessed on 16.12.2018 at http://www.adopsbuzz.com/how-does-ad-serving-work/address.

IAB Türkiye. GDPR. It was accessed on 21.12.2018 at https://www.iabturkiye.org/gdpr address.

Işıklı, Ş. (2014), "Big Data, Epistemology and Ethics Discussions”, Online Academic Journal of Information Technology, Fall - Vol: 5 --/Num:17.

Jagadıshj, H.V., Gehrk, J., Labrinidis, A., Papakontantinou, Y. Patel, J., Rama-Krısnan, J.M.R. ve Shahabi, C. (2014), "Communications of the ACM.", 57 (7): 86-94.

Kurcova, İ. (2005). Marketing on the Internet. Third Edition. Istanbul: Beta Printing Inc.

Korgaonkar, P. \& Wolin, L.D. (2002). Web Usage, Advertising And Shopping : Relationship Patterns. Electronic Networking Applications and Policy, 12(2), 191-204.

McKelvey, N., Curran K. ve Toland, L. (2016). The Challenges of Data Cleansing with Data Warehouses. Effective Big Data Management and Opportunities for Implementation. 7782.

Murray, J. M., Ned, G, (1999). Data Mining and Knowledge Discovery in Databases- An Overview, J.Statists. Vol.41-3. p260.

Özkan Y. (2013). Data Mining Methods. Publishing of Papatya, İstanbul.

Özen Ü., Sarı A. (2007). Attitudes and Behaviors of Internet Users about Internet Advertising: Internet Advertising. Journal of Erciyes University Institute of Social Sciences, 2(23). 
Personal Data Protection Authority. (2018). Law on Protection of Personal Data in 100 Questions, Ankara. It was accessed on 20.12.2018 at https://www.kvkk.gov.tr/SharedFolderServer/CMSFiles/7d5b0a2f-e0ea-41e0-bf0bbc9e43dfb57a.pdf address.

Schneider, R. D. (2012). Hadoop for Dummies. (Special Edition). Mississauga, Canada: John Wiley \& Sons.

Vural İ., Öz M. (2008). Internet as an advertising medium. Journal of Information Technologies, $1(3)$. 